\title{
CHCHD2 inhibits apoptosis by interacting with Bcl-x L to regulate Bax activation
}

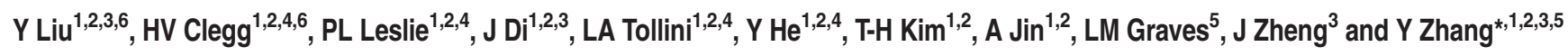

Mitochondrial outer membrane permeabilization (MOMP) is a critical control point during apoptosis that results in the release of pro-apoptotic mitochondrial contents such as cytochrome $c$. MOMP is largely controlled by Bcl-2 family proteins such as Bax, which under various apoptotic stresses becomes activated and oligomerizes on the outer mitochondrial membrane. Bax oligomerization helps promote the diffusion of the mitochondrial contents into the cytoplasm activating the caspase cascade. In turn, Bax is regulated primarily by anti-apoptotic Bcl-2 proteins including Bcl-xL, which was recently shown to prevent Bax from accumulating at the mitochondria. However, the exact mechanisms by which $\mathrm{Bcl}-\mathrm{xL}$ regulates Bax and thereby MOMP remain partially understood. In this study, we show that the small $\mathrm{CHCH}$-domain-containing protein $\mathrm{CHCHD2}$ binds to $\mathrm{Bcl}-\mathrm{xL}$ and inhibits the mitochondrial accumulation and oligomerization of Bax. Our data show that in response to apoptotic stimuli, mitochondrial CHCHD2 decreases prior to MOMP. Furthermore, when CHCHD2 is absent from the mitochondria, the ability of Bcl-xL to inhibit Bax activation and to prevent apoptosis is attenuated, which results in increases in Bax oligomerization, MOMP and apoptosis. Collectively, our findings establish CHCHD2, a previously uncharacterized small mitochondrial protein with no known homology to the $\mathrm{Bcl}-2$ family, as one of the negative regulators of mitochondria-mediated apoptosis.

Cell Death and Differentiation (2015) 22, 1035-1046; doi:10.1038/cdd.2014.194; published online 5 December 2014

Apoptosis is a tightly regulated form of programmed cell death that is critical for proper embryonic development, tissue homeostasis and immune response. Aberrant regulation of apoptosis contributes to a wide range of ailments including autoimmune disorders, neurodegenerative diseases and cancer. Unlike necrotic cell death, apoptosis is a genetic program that is characterized by distinct morphological features such as membrane blebbing, chromatin condensation, DNA fragmentation and cell shrinkage. ${ }^{1}$ In vertebrates, apoptosis can occur through two pathways: extrinsic, or receptor-mediated apoptosis, and intrinsic, or mitochondriamediated apoptosis. Intrinsic apoptosis is induced by cellular stressors such as DNA damage, which lead to mitochondrial outer membrane permeabilization (MOMP), cytochrome $c$ release from the mitochondrial intermembrane space, activation of cysteine proteases (caspases) and induction of apoptosis. Once MOMP occurs, cell death is thought to be inevitable. Therefore, much research has been devoted to elucidating the mechanisms and signaling pathways that govern this critical regulatory point in apoptosis.

MOMP is controlled largely by the B-cell lymphoma 2 (Bcl-2) family of proteins, ${ }^{2}$ all of which contain at least one of four $\mathrm{BH}$ (Bcl-2 homology) domains designated $\mathrm{BH} 1-4$. During apoptosis, the pro-apoptotic Bcl-2 proteins Bax and/or Bak become activated and oligomerize on the mitochondrial outer membrane ${ }^{3}$ increasing mitochondrial membrane permeabilization through a mechanism that is not entirely clear. Bax and Bak are activated by $\mathrm{BH} 3-$ only Bcl-2 family proteins such as Bim, t-Bid and Puma. ${ }^{4-13}$ Conversely, Bax and Bak are inhibited by pro-survival $\mathrm{Bcl}-2$ family proteins such as $\mathrm{Bcl}-2$, Mcl-1 and Bcl-xL.,14-16 Of the pro-survival Bcl-2 family proteins, $\mathrm{Bcl}-2$ is found at the outer mitochondrial membrane, whereas $\mathrm{Bcl}-\mathrm{xL}$ and $\mathrm{Mcl}-1$ localize to the outer mitochondrial membrane and the mitochondrial matrix. ${ }^{17,18}$ Matrix-localized $\mathrm{Bcl}-\mathrm{xL}$ and $\mathrm{Mcl}-1$ have been shown to promote mitochondrial respiration, ${ }^{19}$ suggesting that crosstalk exists between apoptotic pathways and other mitochondria-based biological events. Based on this recent discovery, one might reason that other mitochondrial proteins previously characterized as structural proteins or metabolism-associated enzymes could play an additional intermediate role in the regulation of apoptosis by interacting with $\mathrm{Bcl}-2$ family proteins.

We identified $\mathrm{CHCHD} 2$ in a mass spectrometry-based screen for binding partners of p32, a mitochondrial protein previously shown by our lab to bind and mediate the apoptotic effects of the tumor suppressor p14ARF. ${ }^{20}$ CHCHD2 was subsequently detected in independent screens for proteins that regulate cellular metabolism and migration; ${ }^{21,22}$

\footnotetext{
${ }^{1}$ Department of Radiation Oncology, School of Medicine University of North Carolina at Chapel Hill, Chapel Hill, NC, USA; ${ }^{2}$ Lineberger Comprehensive Cancer Center, School of Medicine University of North Carolina at Chapel Hill, Chapel Hill, NC, USA; ${ }^{3}$ Laboratory of Biological Cancer Therapy, Xuzhou Medical College, Xuzhou, China; ${ }^{4}$ Curriculum in Genetics and Molecular Biology, School of Medicine University of North Carolina at Chapel Hill, Chapel Hill, NC, USA and ${ }^{5}$ Department of Pharmacology, School of Medicine University of North Carolina at Chapel Hill, Chapel Hill, NC, USA

${ }^{*}$ Corresponding author: Y Zhang, Department of Radiation Oncology, School of Medicine University of North Carolina at Chapel Hill, 450 West Drive, Chapel Hill, NC 27514, USA. Tel: +919 966 7713; Fax: +919 966 7681; E-mail: ypzhang@med.unc.edu

${ }^{6}$ These authors contributed equally to this work.

Abbreviations: ARF, alternative reading frame; $\mathrm{CHCHD}$ 2, coiled-coil helix coiled-coil helix domain-containing 2; IP immunoprecipitation; MEF mouse embryonic fibroblast cells; MOMP, mitochondrial outer membrane permeabilization; mPTP, mitochondrial permeability transition pore; PARP poly (ADP-ribose) polymerase; PI, propidium iodide; IP, immunoprecipitation; UV, ultra violet

Received 28.10.13; revised 28.10.14; accepted 29.10.14; Edited by C Borner; published online 05.12.14
} 
however, the functions of $\mathrm{CHCHD} 2$ remain unknown. $\mathrm{CHCHD} 2$ is encoded by the chchd2 gene (coiled-coil helix coiled-coil helix domain-containing 2), which spans 4921 base pairs, contains 4 exons, and is located on human chromosome $7 \mathrm{p} 11.2$, a chromosomal region that is often amplified in glioblastomas. ${ }^{23}$ The protein encoded by the chchd2 gene is ubiquitously expressed ${ }^{24}$ and is relatively small, as it codes for only 151 amino acids. CHCHD2 is well-conserved among different species from humans to yeast, and mouse and human $\mathrm{CHCHD} 2$ share $87 \%$ amino acid sequence identity (Supplementary Figures S1A and S1B). CHCHD2 contains a C-terminal $\mathrm{CHCH}$ (coiled-coil helix coiled-coil helix) domain, which is characterized primarily by four cysteine residues spaced 10 amino acids apart from one another (CX(9)C motif). ${ }^{25}$ The function of the $\mathrm{CHCH}$ domain is not well understood, and the few characterized proteins that harbor this domain have diverse functions. Many $\mathrm{CHCH}$ domaincontaining proteins localize to the mitochondrial inner membrane or the intermembrane space, including Cox12, Cox17, Cox19, Cox23, Mia40 (yeast homolog of human CHCHD4), $\mathrm{CHCHD} 3$ and CHCHD6. Cox17 and Cox19 aid in the assembly of the COX complex, ${ }^{26,27}$ whereas Mia40/Tim40 has been shown to transport proteins into the mitochondrial intermembrane space. ${ }^{28,29}$ Furthermore, $\mathrm{CHCHD3}$ and $\mathrm{CHCHD} 6$ are essential for maintaining the integrity of mitochondrial cristae and thus mitochondrial function. ${ }^{30-32}$ Interestingly, a recent report has shown that $\mathrm{CHCHD6}$ is regulated by DNA damage stress, and alterations in $\mathrm{CHCHD} 6$ expression affect the viability of breast cancer cells in response to genotoxic anticancer drugs. ${ }^{32}$

Despite advances in our understanding of how MOMP and apoptosis are regulated by the $\mathrm{Bcl}-2$ family of proteins, much remains unknown with respect to the mechanisms that lead to Bax activation and oligomerization particularly concerning the roles that mitochondria-associated proteins play in the process. In this study, we characterize the small, mitochondria-localized protein $\mathrm{CHCHD} 2$ as a novel regulator of Bax oligomerization and apoptosis. Furthermore, we show evidence that $\mathrm{CHCHD} 2$ binds to $\mathrm{BCl}-\mathrm{xL}$ at the mitochondria under unstressed conditions. In response to apoptotic stimuli, $\mathrm{CHCHD} 2$ decreases and loses its mitochondria localization, which is accompanied by decreased $\mathrm{Bcl}-\mathrm{xL}-\mathrm{Bax}$ interaction and increased Bax homo-oligomerization and Bax-Bak hetero-oligomerization. Collectively, our results suggest that $\mathrm{CHCHD} 2$ negatively regulates the apoptotic cascade upstream of Bax oligomerization.

\section{Results}

CHCHD2 localizes to the mitochondria. Computational analysis indicates that in addition to its C-terminal $\mathrm{CHCH}$ domain, $\mathrm{CHCHD} 2$ contains two functional domains: a canonical mitochondrial-targeting signal at the $\mathrm{N}$ terminus (MitoProt ${ }^{33}$ ) and a predicted transmembrane element in the central domain, (Figure 1a). To determine whether CHCHD2 indeed localizes to the mitochondria, we examined its subcellular localization by immunofluorescence. U2OS cells were transfected with plasmids expressing C-terminal FLAGtagged $\mathrm{CHCHD} 2,24 \mathrm{~h}$ after which the cells were fixed and subjected to immunofluorescence staining for FLAG. CHCHD2-FLAG localized primarily to the mitochondria as indicated by an overlap with MitoTracker dye signal (Invitrogen, Grand Island, NY, USA; Figure 1b). Next, we generated a rabbit polyclonal antibody specific for $\mathrm{CHCHD2}$, which we used to confirm the localization of endogenous CHCHD2 protein. Once the antibody specificity to $\mathrm{CHCHD} 2$ was confirmed by western blotting (Supplementary Figure S2A) and immunofluorescence staining (Supplementary Figure S2B), immunofluorescence staining for endogenous $\mathrm{CHCHD} 2$ protein was conducted in unstressed U2OS cells. Similarly to our staining results for FLAG-CHCHD2, endogenous $\mathrm{CHCHD} 2$ localized primarily to the mitochondria as revealed by an overlap in signals with the Tim23 mitochondrial marker (Figure 1c). CHCHD2 mitochondrial localization was also observed in HeLa cells (Supplementary Figure S3A) and mouse embryo fibroblasts (MEFs) (Supplementary Figure S3B). To further confirm $\mathrm{CHCHD} 2$ mitochondrial localization, we performed a differential detergent subcellular fractionation, which revealed that $\mathrm{CHCHD} 2$ resides in the mitochondria-enriched heavy membrane fraction consistent with the immunofluorescence results (Figure 1d).

CHCHD2 is important for cell survival from genotoxic stress. Because $\mathrm{CHCHD} 2$ was identified as a binding partner of p32, a mitochondrial protein previously shown to mediate the apoptotic effects of the tumor suppressor p14ARF, ${ }^{20}$ we sought to determine whether CHCHD2 might play a role in cell survival. We first analyzed the effect of CHCHD2 knockdown using two different siRNA duplexes targeting different regions of the $\mathrm{CHCHD} 2$ transcript. U2OS cells were treated with nonspecific control siRNA (NS) or one of two different $\mathrm{CHCHD} 2$ siRNA for $48 \mathrm{~h}$, after which the cells were subjected to various apoptotic stimuli, including UV irradiation, cisplatin, doxorubicin and staurosporine, to determine whether a reduction in $\mathrm{CHCHD} 2$ might affect cell survival. While $\mathrm{CHCHD} 2$ knockdown caused an insignificant decrease in cell survival in the absence of apoptotic stimuli (average 95\% viable cells compared with the control; Figure 2a), CHCHD2 knockdown sensitized U2OS cells to stress-induced cell death, as determined based on the number of cells surviving the treatment. When considering the average number of viable cells in the two $\mathrm{CHCHD} 2$ siRNA-treated groups as a percentage of the control group, UV irradiation reduced cell viability to $64 \%$ (Figure $2 b$ ), cisplatin reduced cell viability to $27 \%$ (Figure 2c), doxorubicin reduced cell viability to $54 \%$ (Figure $2 \mathrm{~d}$ ) and staurosporine reduced cell viability to $69 \%$ (Figure $2 e$ ). The effect of CHCHD2 knockdown was also assessed in HeLa cells treated with UV irradiation and cisplatin. Consistent with the U2OS data, CHCHD2 knockdown sensitized HeLa cells to cell death induced by UV (average $43 \%$ viable cells relative to control) and cisplatin (average 34\% viable cells relative to control; Supplementary Figure S4). We also determined whether $\mathrm{CHCHD} 2$ overexpression might protect cells from stress-induced cell death using CHCHD2-expressing adenoviruses. U2OS cells were infected with adenoviral particles expressing either $\mathrm{CHCHD} 2$ (Ad-CHCHD2) or GFP as a negative control (Ad-Ctl), after which the sensitivity of the cells to UV treatment was assessed. While adenovirus- 
a

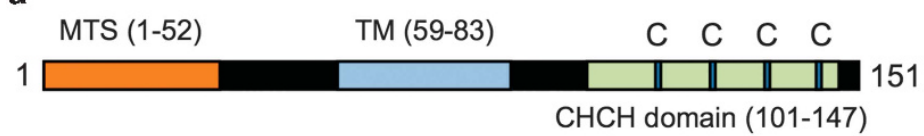

b
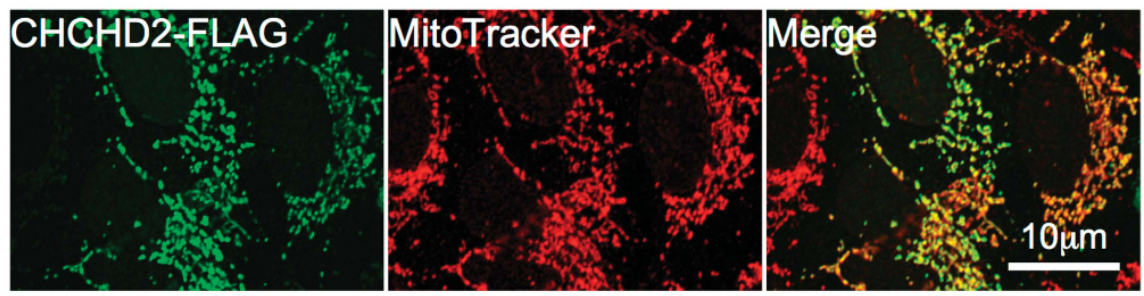

c
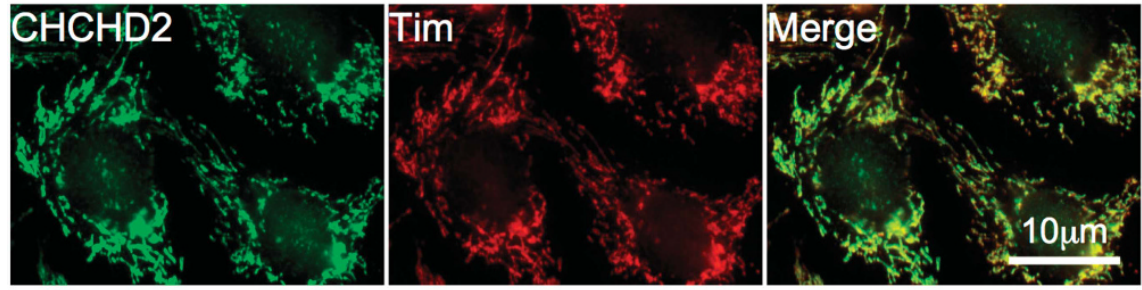

d

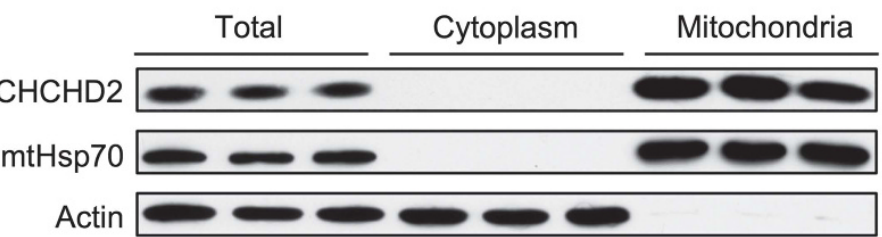

Figure $1 \mathrm{CHCHD} 2$ is a $\mathrm{CHCH}$ domain-containing protein that localizes to the mitochondria. (a) Schematic representation of the $\mathrm{CHCHD} 2$ protein with putative mitochondrialtargeting signal (MTS), predicted transmembrane domain (TM) and $\mathrm{CHCH}$ (coiled-coil-helix coiled-coil helix) domain shown. The $\mathrm{CHCH}$ domain is comprised of four evenly spaced cysteines with the positions indicated. (b) C-terminally tagged CHCHD2-FLAG localizes to the mitochondria in U2OS cells as indicated by co-staining with MitoTracker dye. CHCHD2-FLAG was detected by immunofluorescence with anti-FLAG antibody. (c) Mitochondrial localization of endogenous CHCHD2 in U2OS cells detected by immunofluorescence staining using anti-CHCHD2 antibody as demonstrated by co-staining with the mitochondrial inner membrane protein Tim23 (Tim). (d) Subcellular fractionation of untreated U2OS cells using a differential detergent method shows CHCHD2 present in the mitochondria-enriched heavy membrane fraction (three replicates are shown). Mitochondrial hsp70 (mtHsp70) is included as a marker for the mitochondrial fraction, and actin is included as a marker for the cytoplasmic fraction

mediated overexpression of $\mathrm{CHCHD2}$ yielded no significant effect on unstressed cells, CHCHD2 overexpression effectively protected UV-treated U2OS cells from cell death $(89 \%$ survival relative to $51 \%$ for the control; Figure 2f). These results suggest that $\mathrm{CHCHD} 2$ protects cells from genotoxic stress-induced cell death.

CHCHD2 inhibits MOMP and mitochondrial apoptosis. The pattern of $\mathrm{CHCHD} 2$ expression with respect to cell viability is consistent with the known anti-apoptotic proteins such as Bcl-2 and $\mathrm{Bcl}-\mathrm{xL}$, the inhibition of which does not cause substantial cell death but sensitizes cells to apoptotic stimuli. ${ }^{2}$ This similarity prompted us to further examine whether $\mathrm{CHCHD} 2$ might play a role as an anti-apoptotic protein specifically through the mitochondria-dependent apoptotic pathway. In response to UV treatment, increased cell death was observed in U2OS cells in the presence of CHCHD2 siRNA (Figure 3a). Consistent with an apoptotic phenotype, CHCHD2 knockdown promoted a significant increase in nuclear fragmentation and phosphatidylserine exposure, both of which are hallmarks of apoptosis (Figures $3 \mathrm{~b}$ and $\mathrm{c}$ ). Western blotting was then conducted to examine the expression of molecular markers of apoptosis in UV-treated HeLa cells in the presence or absence of CHCHD2 knockdown. Our results show that upon UV treatment, CHCHD2 expression decreases (Figure 3d, compare lanes 1 and 3). Furthermore, the level of UV-induced cleavage of caspase-3, one of the main proteases involved in the apoptotic cascade, was significantly increased upon knockdown of CHCHD2 (Figure 3d). Consistent with this observation, CHCHD2 knockdown also enhanced UVinduced cleavage of poly(ADP-ribose) polymerase (PARP), a substrate of activated caspase- 3 during apoptosis ${ }^{34}$ (Figure $3 e$ ). In contrast, CHCHD2 overexpression resulted in a reduction in PARP cleavage (Figure $3 \mathrm{f}$ ). Collectively, these data suggest that $\mathrm{CHCHD} 2$ functions as a negative regulator of apoptosis.

Cytochrome $c$ release from the mitochondria is often used as readout for $\mathrm{MOMP}^{35}$ and acts as a trigger for the activation of the caspase cascade, leading to irreversible apoptotic cell death. To determine whether CHCHD2 is involved in the regulation of MOMP, cells were treated with either nonspecific or CHCHD2-specific siRNA for $48 \mathrm{~h}$, after which the cells were subjected to UV irradiation and then assessed by 
immunofluorescence for cytochrome $c$ release. Cells in which cytochrome $c$ was released (indicated by diffuse staining throughout the cell, Figure $3 \mathrm{~g}$ ) were counted as cells with increased MOMP. CHCHD2 knockdown significantly increased the kinetics with which cytochrome $c$ was released, as a greater percentage of cells stained diffusely for cytochrome $c$ in the si-CHCHD2-treated cells relative to the siNS-treated cells at $1 \mathrm{~h}$ (3.9 versus $1.2 \%), 2 \mathrm{~h}$ (14 versus $5 \%$ ), and $4 \mathrm{~h}$ post-UV treatment (35 versus $7.5 \%$ ) (Figure $3 \mathrm{~h}$ ), suggesting that $\mathrm{CHCHD} 2$ plays a role in preventing UVinduced MOMP and cytochrome $c$ release.

Bax activation correlates with CHCHD2 exclusion from the mitochondria. We next sought to identify the mechanism through which $\mathrm{CHCHD} 2$ regulates MOMP and apoptosis. Immunofluorescence staining of cells treated with or without UV irradiation revealed that CHCHD2 loses its mitochondrial localization and shows a diffuse distribution in response to

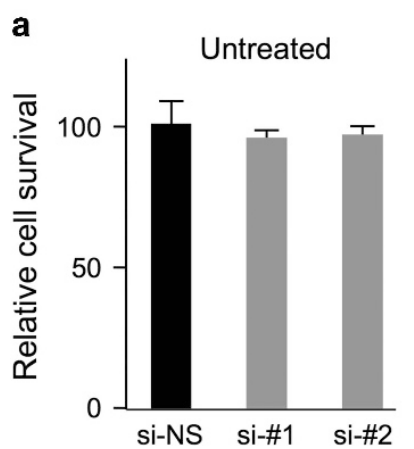

d

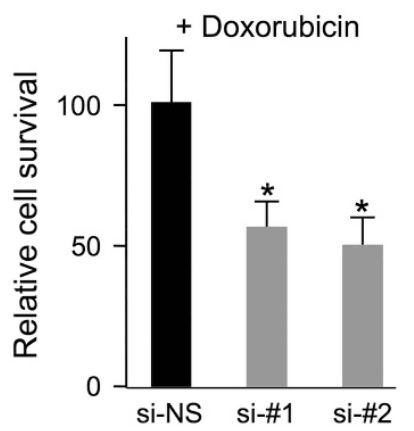

b

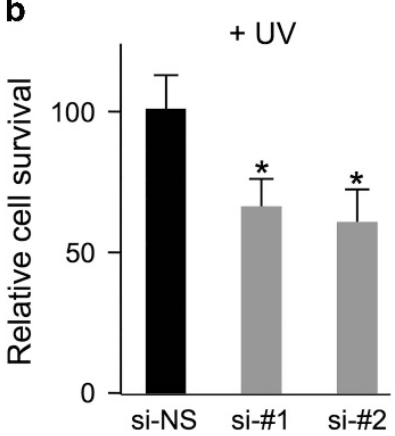

e

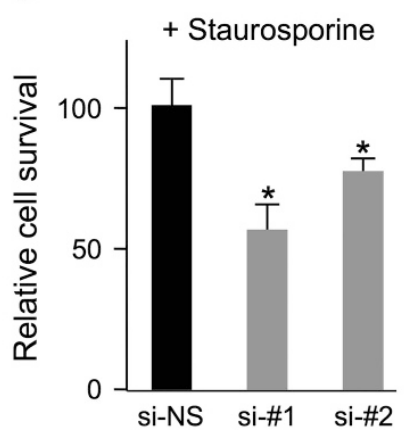

C

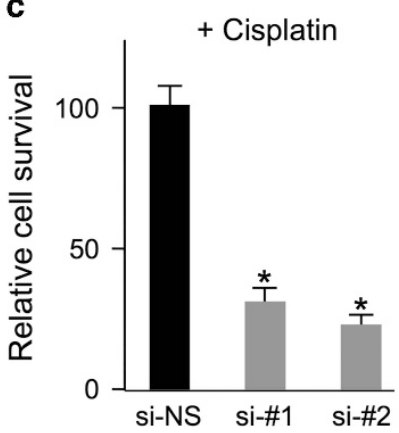

f

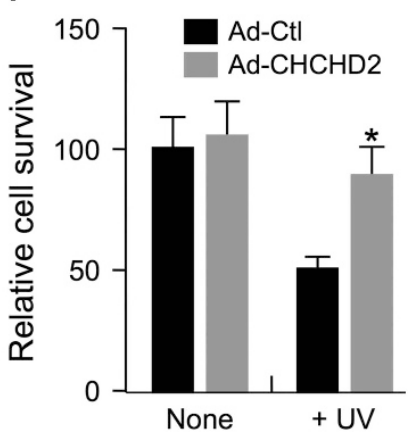

Figure $2 \mathrm{CHCHD2}$ is important for cell survival. (a-e) CHCHD2 knockdown sensitizes U2OS cells to apoptosis induced by a variety of agents. Cells were treated with the indicated siRNA targeting CHCHD2 for $48 \mathrm{~h}$, after which the cells were treated with the following apoptotic stimuli: (b) UV $\left(6 \mathrm{~mJ} / \mathrm{cm}^{2}\right.$ for $\left.24 \mathrm{~h}\right)$, (c) cisplatin $(10 \mu \mathrm{g} / \mathrm{ml}$ for $18 \mathrm{~h})$, (d) doxorubicin $(7.5 \mu \mathrm{M}$ for $18 \mathrm{~h}$ ) and (e) staurosporine ( $200 \mathrm{nM}$ for $18 \mathrm{~h}$ ). The number of cells that survived each treatment was counted in at least 4 random fields of view under each condition. The relative survival is shown as a percentage of the siNS control cells from three independent experimental repeats. (si-\#1 and si-\#2 target two distinct regions of CHCHD2 mRNA as described in the Experimental Procedures section). Error bars denote the S.E. (f) Overexpression of CHCHD2 protects U2OS cells from apoptosis. Cells were infected for $24 \mathrm{~h}$ with control adenovirus expressing GFP (Ad-Ctl) or adenovirus expressing untagged CHCHD2 (Ad-CHCHD2), after which the cells were treated with UV to induce apoptosis $\left(6 \mathrm{~mJ} / \mathrm{cm}^{2}\right.$ for $\left.24 \mathrm{~h}\right)$. The number of cells that survived the treatment is shown as a percentage of the Ad-GFP-infected control cells

\footnotetext{
Figure $3 \mathrm{CHCHD} 2$ inhibits mitochondrial apoptosis and MOMP. (a) CHCHD2 knockdown sensitizes U2OS cells to cell death induced by UV $\left(6 \mathrm{~mJ} / \mathrm{cm}^{2}\right)$. Phase-contrast images are shown for cells treated for $48 \mathrm{~h}$ with nonspecific siRNA (siNS) or CHCHD2 siRNA (si-CHCHD2) with or without UV treatment. (b) CHCHD2 knockdown enhances UVinduced nuclear fragmentation in U2OS cells. Representative DAPI staining is shown for U2OS cells treated for $48 \mathrm{~h}$ with siNS or si-CHCHD2 followed by UV $\left(6 \mathrm{~mJ} / \mathrm{cm}^{2}\right.$ for $24 \mathrm{~h}$ ) or cisplatin $(10 \mu \mathrm{g} / \mathrm{ml}$ for $24 \mathrm{~h})$ treatment. (c) CHCHD2 knockdown enhances UV-induced phosphatidylserine exposure. U2OS cells were treated with UV $\left(6 \mathrm{~mJ} / \mathrm{cm}^{2}\right)$ for $24 \mathrm{~h}$, followed by Annexin-V-FITC and PI-double staining. The cells were then analyzed by flow cytometry. FITC-positive or FITC-PI-double positive cells were counted as apoptotic cells, and the percentages of apoptotic cells from three independent experiments are shown in the graph. The error bars denote the S.E. (d) Caspase-3 cleavage is enhanced in UV-treated cells upon knockdown of CHCHD2. HeLa cells were transfected with CHCHD2 siRNA (D2) or control siRNA (NS) followed by UV treatment (2.5 mJ/cm² for $18 \mathrm{~h}$ ). Cells were then lysed, resolved by SDS-PAGE and probed by western blot for cleaved caspase-3 and CHCHD2. Actin is shown as a loading control. (e) $\mathrm{CHCHD2} \mathrm{knockdown} \mathrm{increases}$ PARP cleavage in response to apoptotic stimuli. HeLa cells were treated with the indicated siRNA for $48 \mathrm{~h}$ and then treated with UV $\left(2.5 \mathrm{~mJ} / \mathrm{cm}^{2}\right.$ for $\left.18 \mathrm{~h}\right)$ to induce apoptosis. Actin is shown as a loading control. (f) CHCHD2 overexpression inhibits PARP cleavage in response to apoptotic stimuli. HeLa cells were infected with adenovirus expressing empty vector (Ctl) or CHCHD2 (D2) for $48 \mathrm{~h}$ and then treated with $\mathrm{UV}\left(2.5 \mathrm{~mJ} / \mathrm{cm}^{2}\right.$ for $\left.18 \mathrm{~h}\right)$ to induce apoptosis. Actin is shown as a loading control. (g, $\left.\mathrm{h}\right) \mathrm{CHCHD2} \mathrm{knockdown}$ increases the rate of MOMP as indicated by cytochrome $c$ release. U2OS cells were pretreated with the caspase inhibitor QVD to prevent post-MOMP cell death and then treated with the indicated siRNA for $48 \mathrm{~h}$ followed by UV irradiation $\left(50 \mathrm{~mJ} / \mathrm{cm}^{2}\right)$ for the indicated amount of time. (g) Representative immunofluorescence images are shown for endogenous cytochrome $c$. (h) Quantification of cells with diffuse cytochrome $c$ staining as a result of UV irradiation at various time points. Cells were counted in at least four random fields of view, and more than 400 cells were counted in total. The graph depicts the percentage of diffusely staining cells of the total cells from three independent experiments. The error bars denote the S.E.
} 
UV irradiation (Figure 4a), an observation that is supported by a rapid decrease in $\mathrm{CHCHD} 2$ mitochondrial levels (Supplementary Figure S5). We did not observe a concomitant increase in cytoplasmic $\mathrm{CHCHD} 2$ in these samples, suggesting that mitochondrial CHCHD2 may be degraded or translocated to other cellular compartments, such as the nucleus, in response to apoptotic stimuli. Interestingly, we observed a subset of cells in which mitochondrial $\mathrm{CHCHD} 2$ was depleted yet cytochrome $c$ remained in the mitochondria, whereas no cells were observed in which cytochrome $c$ was released and $\mathrm{CHCHD} 2$ was retained in the mitochondria (Figure 4b). This observation suggests that the decrease in
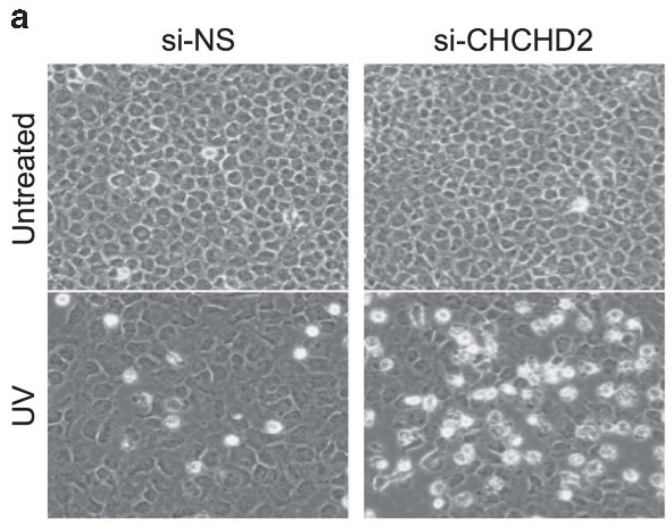

b

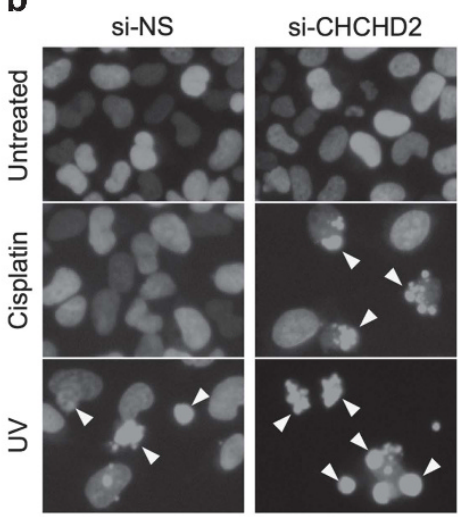

C

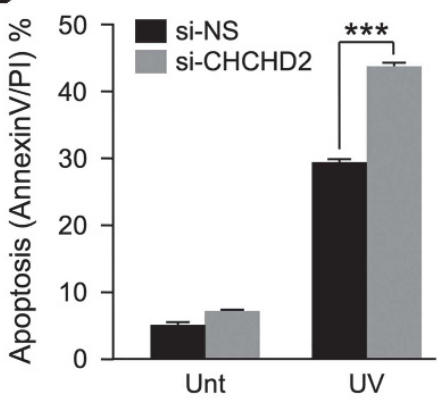

d

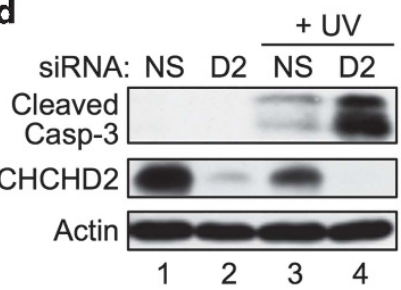

e

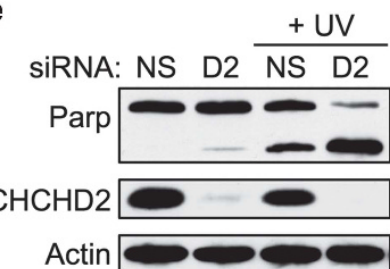

f

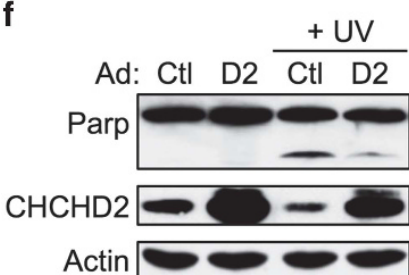

g

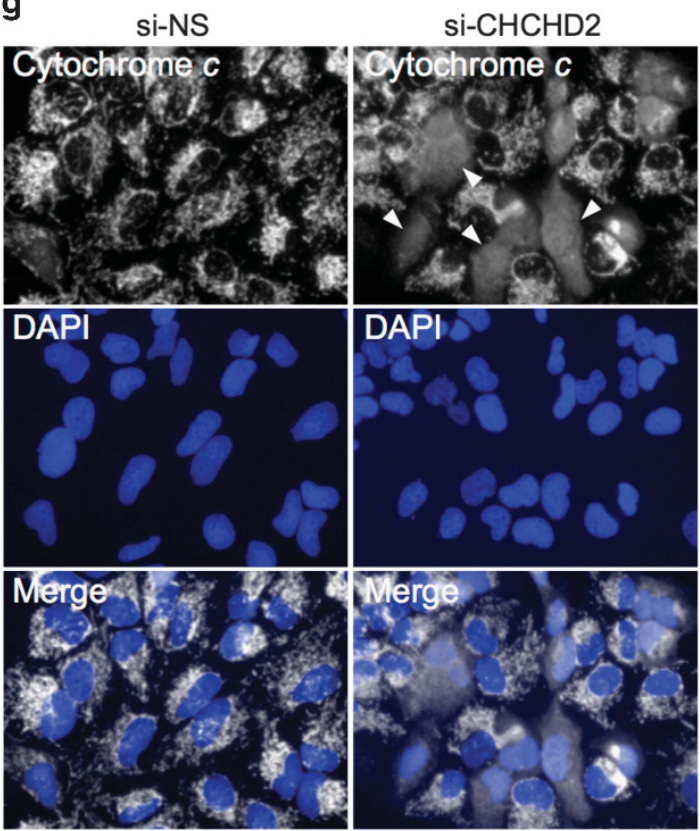

h

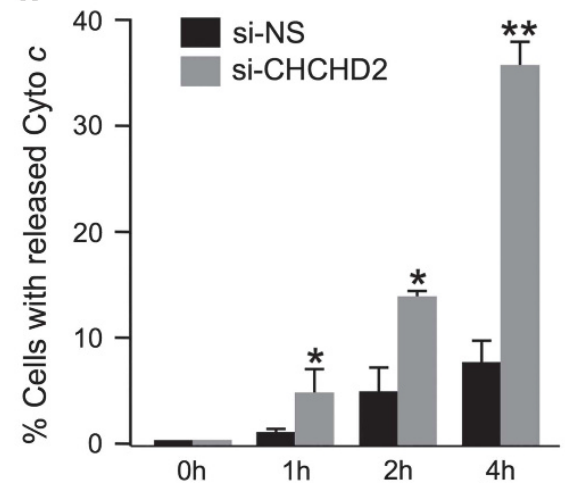



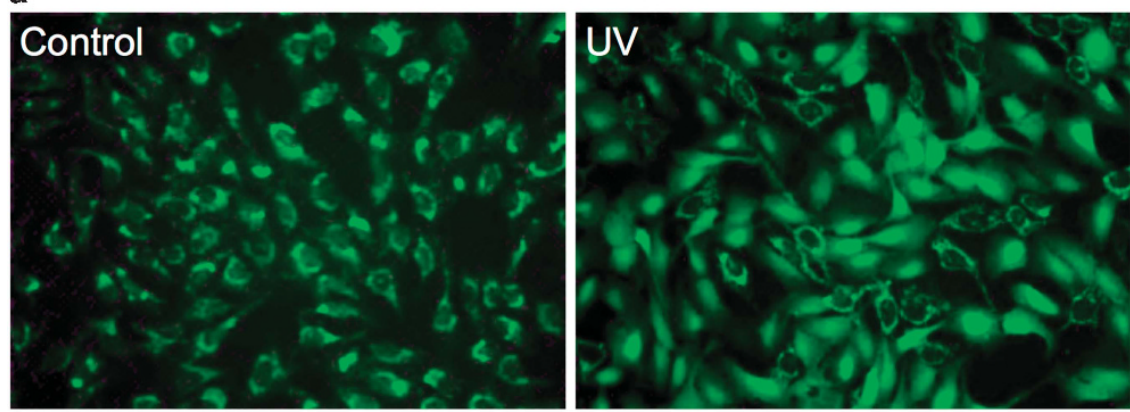

b
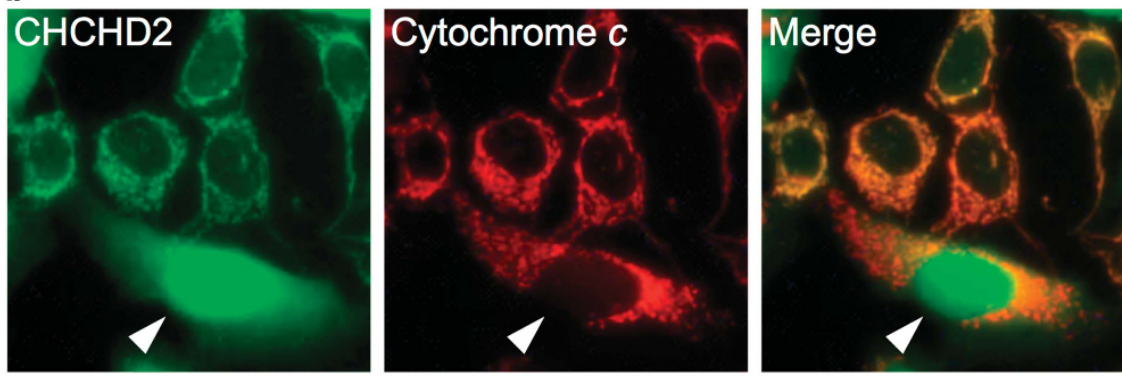

C

d
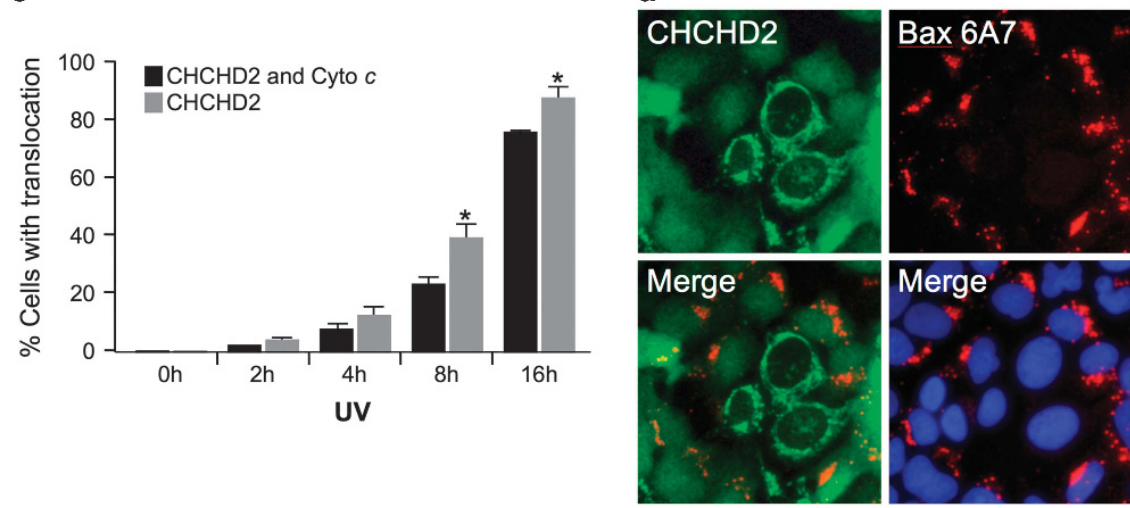

Figure 4 Loss of mitochondrial CHCHD2 correlates with Bax activation. (a) Mitochondrial CHCHD2 is depleted in response to apoptotic stimuli. U2OS cells were pretreated with QVD for $1 \mathrm{~h}$ and then treated with UV $\left(6 \mathrm{~mJ} / \mathrm{cm}^{2}\right)$ for $24 \mathrm{~h}$ where indicated. Endogenous CHCHD2 was detected by immunofluorescence staining. (b) Loss of mitochondrial $\mathrm{CHCHD} 2$ occurs prior to cytochrome $c$ release in response to apoptotic stimuli. Immunofluorescence staining of endogenous $\mathrm{CHCHD2}$ (green) and cytochrome $c$ (red) in UV-treated $\left(6 \mathrm{~mJ} / \mathrm{cm}^{2}\right.$ for $12 \mathrm{~h}$ ) U2OS cells shows that in some cells cytochrome $c$ remains in the mitochondria after mitochondrial CHCHD2 is depleted (indicated by the arrow). (c) Loss of mitochondrial CHCHD2 occurs more rapidly than cytochrome $c$ release. U2OS cells were pretreated with the caspase inhibitor QVD (10 $\mu \mathrm{M}$ for $1 \mathrm{~h}$ ), after which the cells were treated with UV $\left(6 \mathrm{~mJ} / \mathrm{cm}^{2}\right)$ to induce apoptosis and then fixed at the indicated time points. Cells were subjected to immunofluorescence staining for endogenous $\mathrm{CHCHD} 2$ and cytochrome $c$. The percentage of cells with diffuse $\mathrm{CHCHD} 2$ staining and cytochrome $c$ staining was quantified at each time point and are represented on the graph as the averages of three independent experiments. For each experiment, at least four random fields of view were counted comprising at least 400 cells. Error bars denote the S.E. (d) Bax activation correlates with the loss of mitochondrial CHCHD2 in U2OS cells. Cells were treated with UV $\left(6 \mathrm{~mJ} / \mathrm{cm}^{2}\right.$ for $\left.24 \mathrm{~h}\right)$ to induce apoptosis. Immunofluorescence staining was performed to detect endogenous CHCHD2 (green) and activated Bax (6A7 antibody, red). Activated Bax is observed only in cells in which mitochondrial CHCHD2 is depleted. Nuclei were stained with DAPI

mitochondrial CHCHD2 probably occurs prior to cytochrome $c$ release. To test this hypothesis, we examined cytochrome $c$ and $\mathrm{CHCHD2}$ localization in UV-treated U2OS cells and quantified the percentage of cells displaying diffuse $\mathrm{CHCHD} 2$ staining and cytochrome $c$ release at several time points. Cells were pretreated with the pan-caspase inhibitor Q-VDOPh (QVD) to prevent cell death downstream of cytochrome $c$ release, thereby preserving cells with released cytochrome $c$ and allowing these cells to be assessed. Cells were treated with UV irradiation, after which the cells were fixed for immunofluorescence staining at the indicated time points.
At each time point, we observed a greater percentage of cells, displaying diffuse $\mathrm{CHCHD} 2$ staining than cytochrome $c$ release (Figure 4c).

Although several models, including ones based on the opening of the mitochondrial permeability transition pore (mPTP) and the formation of the cytochrome $c$-conducting channel have been proposed to play key roles in MOMP, ${ }^{36}$ the vast majority of models explaining MOMP converge at the proapoptotic Bcl-2 family members Bax and/or Bak. Surprisingly, we noted that in cells exposed to an apoptotic dose of UV irradiation, Bax activation was observed only in cells in which 
mitochondrial $\mathrm{CHCHD} 2$ was lost, whereas cells that retained mitochondrial $\mathrm{CHCHD} 2$ consistently stained negative for active Bax (Figure 4d). Thus, in cells undergoing apoptosis, Bax activation correlated strictly with the loss of mitochondrial CHCHD2, suggesting that mitochondrial $\mathrm{CHCHD2}$ may be functionally involved in the negative regulation of $\mathrm{Bax}$ activation.

$\mathrm{Bcl}-\mathrm{xL}$ is important for $\mathrm{CHCHD2}$ to protect cells from apoptosis. The correlation between the loss of mitochondrial $\mathrm{CHCHD} 2$ and Bax activation suggests that $\mathrm{CHCHD} 2$ likely inhibits apoptosis by controlling Bax activation and subsequent MOMP. To further investigate this observation, co-immunoprecipitation (co-IP) experiments were conducted to determine whether $\mathrm{CHCHD} 2$ interacts directly with $\mathrm{Bcl}-2$ family proteins-the best characterized network of proteins involved in apoptosis regulation. After probing a number of Bcl-2 family members (Supplementary Figure S6), we found that endogenous $\mathrm{CHCHD2}$ interacts with ectopically expressed $\mathrm{FLAG}-\mathrm{Bcl}-\mathrm{xL}$ in reciprocal co-IP experiments (Figures $5 \mathrm{a}$ and $\mathrm{b}$ ). We were unable to detect endogenous $\mathrm{Bcl}-\mathrm{xL}-\mathrm{CHCHD} 2$ binding, which might suggest that this interaction is transient resulting in a small fraction of $\mathrm{Bcl}-$
$\mathrm{xL}-\mathrm{CHCHD} 2$ binding at any given time. $\mathrm{Bcl}-\mathrm{xL}$ is an important negative regulator of apoptosis that functions by inhibiting Bax and Bak activation. ${ }^{15,37}$ Based on our observed interaction between the two anti-apoptotic proteins $\mathrm{CHCHD} 2$ and $\mathrm{BCl}-\mathrm{xL}$, we sought to determine to what extent their interaction might be required to inhibit apoptosis. To this end, $\mathrm{Bcl}-\mathrm{xL}$ was overexpressed in the presence or absence of siCHCHD2 in cells. Consistent with previous studies, overexpression of $\mathrm{Bcl}-\mathrm{xL}$ inhibited UV-induced apoptosis in all samples tested (Figure 5c: 23.7 versus 11.5\% apoptotic cells in the presence of siNS (black bars), and 35.4 versus $22.7 \%$ apoptotic cells in the presence of si-CHCHD2 (gray bars)); however, knockdown of $\mathrm{CHCHD} 2$ reduced the protective effect of Bcl-xL overexpression (Figure 5c: 11.5\% apoptotic cells in siNS sample versus $22.7 \%$ apoptotic cells in si$\mathrm{CHCHD} 2$ sample). These results suggest that although $\mathrm{Bcl}-$ $\mathrm{xL}$ retains the ability to inhibit apoptosis to an extent in the absence of $\mathrm{CHCHD} 2, \mathrm{CHCHD} 2$ enhances the pro-survival function of $\mathrm{Bcl}-\mathrm{xL}$. Conversely, the anti-apoptotic function of $\mathrm{CHCHD} 2$ is largely ablated upon depletion of $\mathrm{Bcl}-\mathrm{xL}$ (Figures $5 d$ and e and Supplementary Figure S7), suggesting that the anti-apoptotic function of $\mathrm{CHCHD2}$ requires $\mathrm{Bcl}-\mathrm{xL}$. a

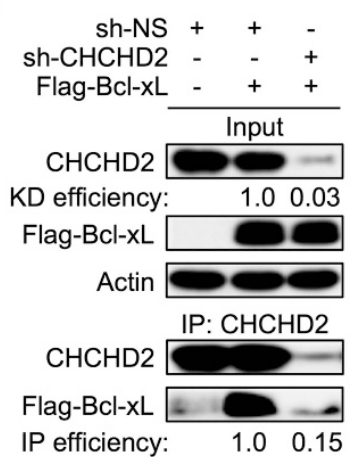

C

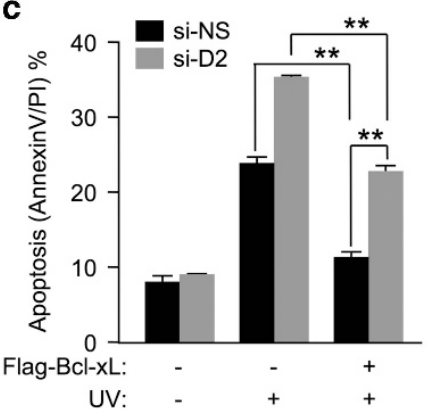

b
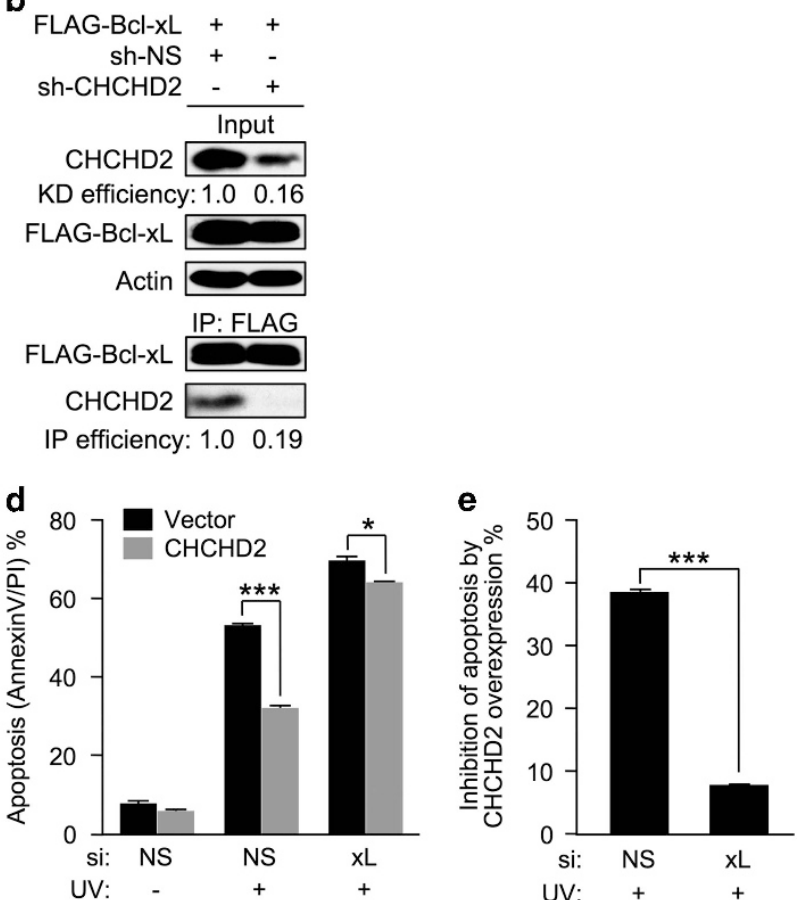

Figure $5 \mathrm{Bcl}-\mathrm{xL}$ is required for the anti-apoptotic function of $\mathrm{CHCHD} 2$. (a, b) $\mathrm{CHCHD} 2$ interacts with $\mathrm{Bcl}-\mathrm{xL}$. U2OS cells stably expressing nonspecific (sh-NS) or CHCHD2specific (sh-CHCHD2) shRNA were transfected with FLAG-Bcl-xL for $24 \mathrm{~h}$ and then lysed with $1 \%$ CHAPS buffer. Lysates containing $1 \mathrm{mg}$ of total protein were immunoprecipitated with antibodies against CHCHD2 (a) or FLAG (b). Samples were analyzed by western blotting with the indicated antibodies. Input loading represents $5 \%$ of the total cell lysate used for IP. (c) CHCHD2 enhances, but is not required for, the apoptosis-inhibiting function of Bcl-xL. U2OS cells were treated with siNS or si-CHCHD2 for $48 \mathrm{~h}$, followed by transient transfection with FLAG-Bcl-xL or empty vector for another $24 \mathrm{~h}$ and then were treated by UV irradiation $\left(6 \mathrm{~mJ} / \mathrm{cm}^{2}\right)$ for $24 \mathrm{~h}$. The cells were then stained with Annexin-V-FITC/PI and analyzed by flow cytometry. The means of the percentages of apoptotic cells from three independent experiments are shown, and the error bars denote the S.E. (d, e) The inhibitory function of CHCHD2 on apoptosis is compromised by knockdown of Bcl-xL. U2OS cells stably expressing transfected CHCHD2 were treated with the indicated siRNA constructs for $48 \mathrm{~h}$ followed by UV irradiation treatment $\left(25 \mathrm{~mJ} / \mathrm{cm}^{2}\right)$ for $18 \mathrm{~h}$ as indicated. Cells were then stained with Annexin-V-FITC/PI and analyzed by flow cytometry. (d) The mean of the percentages of apoptotic cells from three independent experiments are shown, and the error bars denote the S.E. (e) The apoptosis inhibition ratio was calculated based on the apoptosis percentages shown in $\mathrm{d}$. The difference between the percentage of apoptotic cells with $\mathrm{CHCHD} 2$ overexpression and the percentage of apoptotic cells with empty vector was divided by the percentage of apoptosis in cells transfected with empty vector for each UV-treated sample. The error bars denote the S.E. 
CHCHD2 cooperates with Bcl-xL to regulate Bax in response to apoptotic stimuli. A recent study has shown that $\mathrm{Bcl}-\mathrm{xL}$ regulates $\mathrm{Bax}$ through a direct binding mechanism resulting in Bax retrotranslocation from the mitochondria to the cytosol, which prevents Bax from forming active oligomers. ${ }^{38}$ During apoptosis, Bcl-xL-Bax binding is disrupted, and Bax accumulates at the mitochondria resulting in MOMP and apoptosis. ${ }^{39}$ Given the functional correlation between the loss of mitochondrial $\mathrm{CHCHD} 2$ and $\mathrm{Bax}$ activation (Figure 4) and the interaction of $\mathrm{CHCHD} 2$ with $\mathrm{Bcl}-\mathrm{xL}$, we examined whether $\mathrm{CHCHD} 2$ affects the function of $\mathrm{Bcl}-\mathrm{xL}$ and Bax. To this end, U2OS cells stably expressing CHCHD2 shRNA were transfected with HA-Bax and FLAG$\mathrm{Bcl}-\mathrm{xL}$, and were subjected to immunoprecipitation with an $\mathrm{HA}$ antibody. $\mathrm{CHCHD} 2$ knockdown reduced the level of Bcl$\mathrm{xL}-\mathrm{Bax}$ binding by $\sim 40 \%$, suggesting that $\mathrm{CHCHD} 2$ is important but not required for $\mathrm{Bcl}-\mathrm{xL}-\mathrm{Bax}$ interaction (Figure 6a). Likewise, CHCHD2 knockdown also increased the presence of Bax protein in the mitochondria-enriched heavy membrane fraction, particularly after cells were treated with UV irradiation (Figure 6b, compare lanes 9 and 10 with 11 and 12).

We then examined whether $\mathrm{CHCHD} 2$ depletion could affect Bax activation. Activated Bax can be detected by immunofluorescence staining using anti-Bax 6A7 antibody, which recognizes an $\mathrm{N}$-terminal epitope hidden in inactive Bax protein but exposed due to the conformational changes that occur during Bax activation. To determine whether $\mathrm{CHCHD} 2$ affects Bax activation, cells were treated with $\mathrm{CHCHD} 2$ siRNA for $48 \mathrm{~h}$, after which apoptosis was induced by UV irradiation, and Bax activation was examined by immunofluorescence staining with anti-Bax $6 \mathrm{~A} 7$ antibody. CHCHD2 knockdown did not affect Bcl-xL localization (Supplementary Figure S8) but significantly increased UV treatment-induced Bax activation, as indicated by strong immunofluorescence staining of cells treated with si-CHCHD2 and UV irradiation (Figures $6 \mathrm{c}$ and d) and increased levels of $6 \mathrm{~A} 7$ antibody-reactive Bax protein by western blotting (Figure 6e). CHCHD2 knockdown also increased Bak protein levels and Bax-Bak hetero-oligomer formation (Figure $6 \mathrm{e}$ ), suggesting that $\mathrm{CHCHD} 2$ is functionally associated with the activation of Bax and Bak. To directly examine Bax oligomerization, mitochondria were isolated from cells treated with si-CHCHD2 and UV irradiation and then treated with trypsin, which degrades Bax monomers but not
Bax oligomers. ${ }^{40}$ As shown in Figure $6 \mathrm{f}, \mathrm{CHCHD} 2$ knockdown increased the level of trypsin-resistant Bax. Altogether, our data suggest that $\mathrm{CHCHD} 2$ inhibits apoptosis at least in part by cooperating with $\mathrm{Bcl}-\mathrm{xL}$ to regulate $\mathrm{Bax}$.

\section{Discussion}

One of the pro-survival functions of $\mathrm{Bcl}-\mathrm{xL}$ is its ability to inhibit Bax and Bak-induced formation of pores in the outer mitochondrial membrane. ${ }^{41}$ However, the mechanism through which $\mathrm{Bcl}-\mathrm{xL}$ regulates $\mathrm{Bax}$ and $\mathrm{Bak}$ is not sufficiently understood and has been a subject of debate. Some recent studies have shown that $\mathrm{Bcl}-\mathrm{xL}$ inhibits $\mathrm{Bax}$ by promoting $\mathrm{Bax}$ retrotranslocation to the cytoplasm. ${ }^{38,42}$ Furthermore, these studies demonstrated that Bax continually cycles between the cytoplasm and the mitochondria. In non-apoptotic cells, when Bax arrives at the mitochondria $\mathrm{Bcl}-\mathrm{xL}$ binds with $\mathrm{Bax}$ to retrotranslocate Bax to the cytoplasm. During apoptosis, the Bcl-xL-Bax interaction is disrupted, leading to mitochondrial accumulation and activation of Bax. However, another study has shown that both $\mathrm{Bax}$ and $\mathrm{Bcl}-\mathrm{xL}$ exist in a dynamic equilibrium between the cytosol and the mitochondria, and instead of actively retrotranslocating $\mathrm{Bax}, \mathrm{Bcl}-\mathrm{xL}$ stabilizes and inhibits a portion of membrane-associated Bax as a result of the disruption of survival signals. ${ }^{43}$ In both of these models, $\mathrm{Bcl}-\mathrm{xL}$ plays a key role in inhibiting Bax activation by retrotranslocating Bax to the cytosol or by directly binding to membrane-bound Bax to inhibit Bax activation.

Our study establishes $\mathrm{CHCHD} 2$ as an anti-apoptotic protein residing in the mitochondria, where it regulates MOMP during apoptosis. Through a mechanism that is not yet clear, $\mathrm{CHCHD} 2$ interacts with $\mathrm{Bcl}-\mathrm{xL}$ to regulate Bax localization, activation and oligomerization. In response to apoptotic stimuli, CHCHD2 levels decrease in the mitochondria. The decrease in mitochondrial $\mathrm{CHCHD} 2$ levels correlates with a loss in the ability of $\mathrm{Bcl}-\mathrm{xL}$ to suppress Bax, thereby allowing MOMP and apoptosis to proceed (Figure $6 \mathrm{~g}$ ). Our findings reveal a novel component of the intrinsic apoptosis pathway and contribute to our knowledge of the physiological events that take place at the mitochondria with respect to Bax localization, activation and oligomerization and ultimately MOMP and apoptosis.

How the interaction between $\mathrm{CHCHD2}$ and $\mathrm{Bcl}-\mathrm{xL}$ affects $\mathrm{BCl}-\mathrm{xL}$ inhibition of Bax activation remains unclear. $\mathrm{BCl}-\mathrm{xL}$ and

\footnotetext{
Figure $6 \mathrm{CHCHD} 2$ cooperates with Bcl-xL to regulate Bax translocation, oligomerization and activation. (a) CHCHD2 knockdown reduces Bcl-xL-Bax interaction. U2OS cells stably expressing nonspecific (sh-NS) or CHCHD2-specific (sh-CHCHD2) shRNA were transfected with HA-Bax and FLAG-Bcl-xL for $24 \mathrm{~h}$ and then were lysed with $1 \%$ CHAPS buffer. Cell lysates containing $1 \mathrm{mg}$ of total protein were immunoprecipitated with HA-specific antibody. Samples were analyzed by western blotting with the indicated antibodies. (b) CHCHD2 knockdown increases mitochondrial translocation of Bax. HeLa cells were transfected with the indicated siRNA for $48 \mathrm{~h}$ and then were treated with UV irradiation $\left(25 \mathrm{~mJ} / \mathrm{cm}^{2}\right.$ for $3 \mathrm{~h}$ ) to induce apoptosis. Subcellular fractionation was performed, and the total cell lysates (Total), cytosolic fractions (Cyto) and mitochondrial fractions (Mito) were analyzed by western blotting with the indicated antibodies. (c, d) CHCHD2 knockdown augments Bax activation. U2OS cells were treated with the indicated siRNA for $48 \mathrm{~h}$ followed by UV irradiation to induce apoptosis $\left(6 \mathrm{~mJ} / \mathrm{cm}^{2}\right)$. Cells were fixed $24 \mathrm{~h}$ later and stained for activated Bax (6A7). Red staining indicates the presence of activated Bax accumulated on the mitochondrial surface. (e) CHCHD2 knockdown augments mitochondrial Bak accumulation and Bax-Bak hetero-oligomerization. Mitochondria were enriched by fractionation and then were lysed with $1 \%$ CHAPS lysis buffer. Following lysis, $500 \mu \mathrm{g}$ of mitochondrial lysate was immunoprecipitated with Bax (6A7) or Bak antibody. Samples were analyzed by western blotting with the indicated antibodies. (f) CHCHD2 knockdown increases trypsin-resistant, oligomerized Bax (TR-Bax). A trypsin resistance assay was conducted on isolated mitochondria after treating HeLa cells with the indicated siRNA for $48 \mathrm{~h}$ followed by UV irradiation. Mitochondria were treated with trypsin to digest monomeric Bax, lysed, resolved by SDS-PAGE and then probed by immunoblotting. (g) Schematic depiction of CHCHD2 function. Apoptotic stimuli such as UV induce loss of mitochondria $\mathrm{CHCHD2}$, thereby facilitating release of Bax from Bcl-xL-dependent inhibition. Bax then accumulates on the mitochondria and forms oligomers to induce MOMP and apoptosis
} 
a

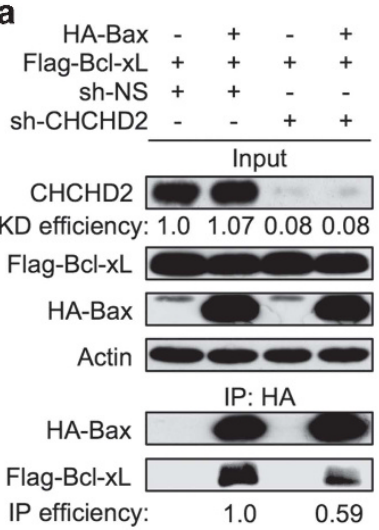

C
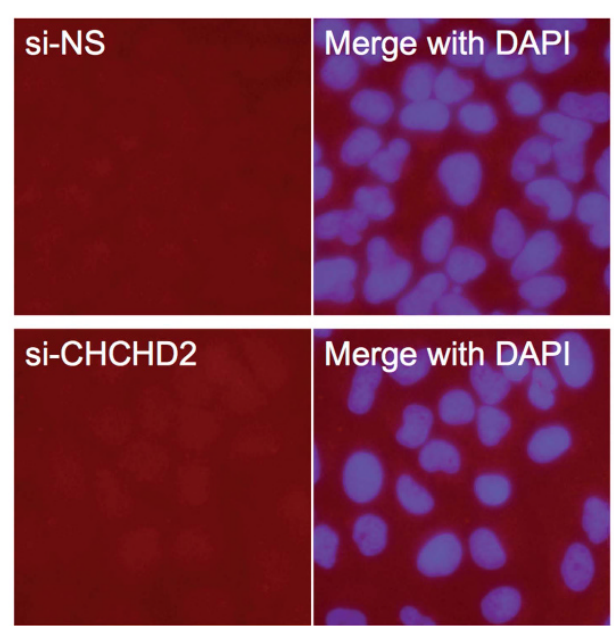

\section{b}

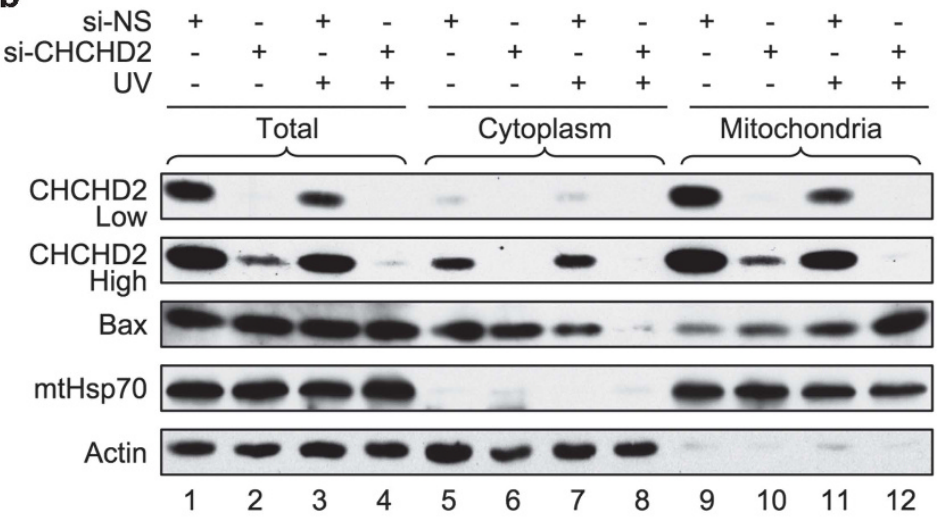

d
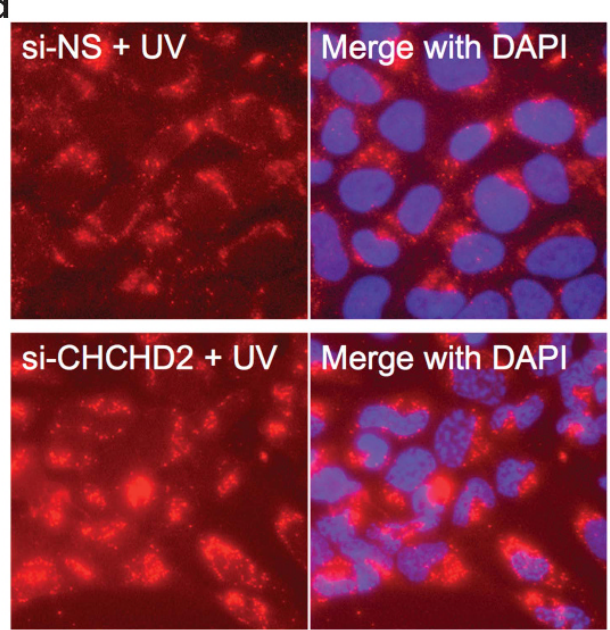

e

si-NS + - + si-CHCHD2 - + - +

UV $\frac{-\quad+\quad+}{\text { Input }}$

$\mathrm{CHCHD} 2 \longrightarrow-$

Bak $-\cdots$

$\mathrm{Bax}=-\infty$

$\mathrm{Hsp} 70 \Longrightarrow$

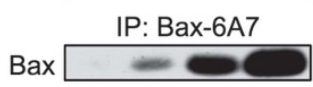

IP: Bak

Bak

Bax $\div$ f

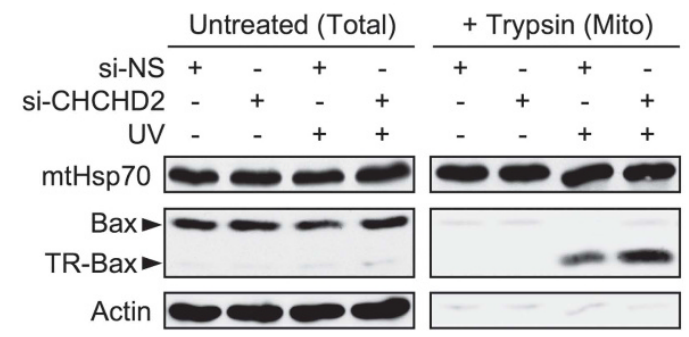

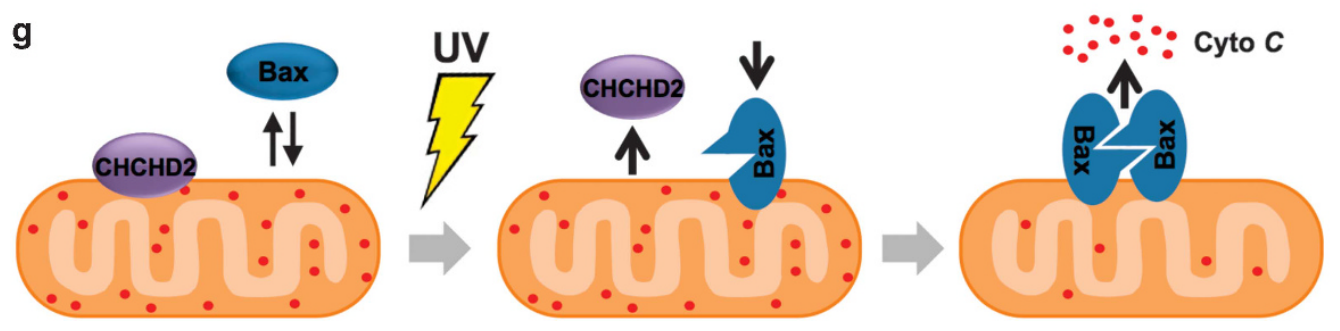


Bax are thought to exist in equilibrium in the cytosol and the mitochondria, and apoptotic stress can shift this equilibrium to favor a membrane-bound form of oligomerized Bax. ${ }^{38,43,44}$ Some evidence suggests that Bax is retrotanslocated by $\mathrm{Bcl}-\mathrm{xL}$ through the C-terminal helix of $\mathrm{Bcl}-\mathrm{xL} ;{ }^{38,42}$ however, how $\mathrm{Bcl}-\mathrm{xL}$ itself switches between its soluble form and the membrane-bound form and how Bcl-xL maintains the dynamic equilibrium between the cytosol and the mitochondria remain unknown. In the context of previous studies, our results identify $\mathrm{CHCHD} 2$ as a novel $\mathrm{Bcl}-\mathrm{xL}$-interacting protein and allow us to speculate on a model whereby mitochondrialocalized $\mathrm{CHCHD} 2$ interacts with $\mathrm{Bcl}-\mathrm{xL}$ by a kiss-and-run interaction to help maintain the proper $\mathrm{Bcl}-\mathrm{xL}$ equilibrium between the cytosol and the mitochondrial membrane in the absence of apoptotic stimuli. In the presence of $\mathrm{CHCHD2}$, a large portion of $\mathrm{Bcl}-\mathrm{xL}$ resides at the mitochondria where it can bind and inhibit Bax. However, in response to apoptotic stimuli, mitochondrial $\mathrm{CHCHD} 2$ levels decrease allowing the $\mathrm{Bcl}-\mathrm{xL}$ equilibrium to shift favoring the cytosolic form, resulting in Bax accumulation and activation on the mitochondria culminating in apoptosis (Figure $6 \mathrm{~g}$ ). Future studies elucidating the residues and upstream factors involved in regulating $\mathrm{CHCHD} 2-\mathrm{BCl}-\mathrm{xL}$ binding will contribute to our understanding of the anti-apoptotic function of $\mathrm{CHCHD2}$.

In response to apoptotic stimuli, $\mathrm{CHCHD} 2$ level decreases and loses its mitochondrial localization. The signals that induce the loss of mitochondrial CHCHD2 are unknown, and elucidating these triggers will be an important area for further investigation. In other $\mathrm{CHCH}$-domain-containing proteins, the disulfide bonds between the cysteines of this domain can be altered (generating various hairpin and oligomer formations) depending on the oxidative-reductive state of the immediate environment of the protein. ${ }^{26,45}$ One possibility that merits further investigation is that the $\mathrm{CHCH}$ domain of $\mathrm{CHCHD} 2$ functions as a sensor of redox changes that take place at the mitochondria during apoptosis, resulting in the appropriate $\mathrm{CHCHD} 2$ conformational changes to regulate Bax oligomerization and MOMP. Another possibility is that in addition to regulating apoptosis at the mitochondrial membrane, $\mathrm{CHCHD} 2$ may play an ancillary role in the cytoplasm and/or nucleus. Indeed, a recent study reported that $\mathrm{CHCHD} 2$ functions as a transcription factor to regulate cytochrome $c$ oxidase expression and facilitate mitochondrial electron transport chain flux. ${ }^{46}$ If so, our data indicate that such a role may not be required for apoptosis, as siRNA-mediated inhibition of $\mathrm{CHCHD} 2$ enhances rather than prevents apoptosis.

Evasion of apoptosis is one of the hallmarks of cancer, and cancers often exhibit reduced expression of pro-apoptotic proteins and/or increased expression of anti-apoptotic proteins. ${ }^{47,48}$ Based on the analysis of mRNA microarray expression data obtained from the Oncomine database, $\mathrm{CHCHD} 2$ is overexpressed in a diverse group of cancers, including prostate, lung, kidney, skin, brain, mesothelium, head and neck and two types of leukemias (Table 1)..$^{49-61}$ The upregulation of $\mathrm{CHCHD} 2$ in cancers along with our data showing that $\mathrm{CHCHD} 2$ knockdown sensitizes cancer cells to chemotherapeutic agents suggests that further research investigating $\mathrm{CHCHD} 2$ as a cancer biomarker or as a potential chemosensitizing drug target may be warranted.
Table 1 Increased expression ${ }^{a}$ of $\mathrm{CHCHD} 2$ mRNA in cancers

\begin{tabular}{|c|c|c|c|}
\hline Cancer type & $\begin{array}{c}\text { Fold } \\
\text { increase }\end{array}$ & $P$-value & Dataset \\
\hline Breast, ductal carcinoma & 1.754 & $4.10 \mathrm{E}-10$ & Sorlie et al. ${ }^{49}$ \\
\hline Cervical cancer & 1.656 & $2.00 \mathrm{E}-03$ & Pyeon et al. ${ }^{50}$ \\
\hline Glioblastoma & 1.579 & $5.57 \mathrm{E}-05$ & Liang et al. ${ }^{51}$ \\
\hline Leukemia, acute myeloid & 2.032 & $2.16 \mathrm{E}-05$ & Andersson et al..$^{52}$ \\
\hline $\begin{array}{l}\text { Leukemia, childhood T-cell acute } \\
\text { lymphoblastic }\end{array}$ & 2.913 & $1.56 \mathrm{E}-05$ & Andersson et al..$^{52}$ \\
\hline Lung adenocarcinoma & 1.564 & $3.07 \mathrm{E}-13$ & Landi et al. ${ }^{53}$ \\
\hline Lymphoma, diffuse B-cell & 1.846 & $1.00 \bar{E}-02$ & Storz et al. ${ }^{54}$ \\
\hline Melanoma & 4.163 & $4.77 \mathrm{E}-04$ & Haqq et al. ${ }^{55}$ \\
\hline Mesothelioma, pleural malignant & 2.018 & $1.62 \mathrm{E}-06$ & Gordon et al. ${ }^{56}$ \\
\hline Myeloma, smoldering & 2.018 & $3.23 \mathrm{E}-05$ & Zhan et al. ${ }^{57}$ \\
\hline Neuroblastoma & 1.755 & $8.76 \mathrm{E}-04$ & Albino et al. ${ }^{58}$ \\
\hline Oral cavity carcinoma & 2.827 & $2.05 \mathrm{E}-06$ & Pyeon et al. ${ }^{50}$ \\
\hline Oropharyngeal carcinoma & 2.325 & $3.85 E-06$ & Pyeon et al..$^{50}$ \\
\hline Pancreatic carcinoma & 1.52 & $3.48 \mathrm{E}-05$ & Pei et al. ${ }^{59}$ \\
\hline Prostate carcinoma & 2.13 & $1.98 \mathrm{E}-04$ & Tomlins et al. ${ }^{60}$ \\
\hline Renal cell carcinoma, papillary & 1.591 & $1.30 \mathrm{E}-04$ & Yusenko et al. ${ }^{61}$ \\
\hline Tongue carcinoma & 2.231 & $1.12 \mathrm{E}-05$ & Pyeon et al. ${ }^{50}$ \\
\hline
\end{tabular}

Microarray data obtained from Oncomine (Compendia Bioscience, Ann Arbor, MI, USA). Cancers with $\geq 1.5$-fold increase in Sumi-1 expression and $P$-value $\leq 0.01$ are shown

${ }^{\mathrm{a}}$ Compared with expression in corresponding normal tissues

\section{Materials and Methods}

Cell culture, transfection, and apoptotic treatments. U2OS and HeLa cells were obtained from ATCC (Manassas, VA, USA), and MEFs were harvested at E13.5. All cells were cultured in a $37^{\circ} \mathrm{C}$ incubator with $5 \% \mathrm{CO}_{2}$ in DMEM supplemented with $10 \% \mathrm{FBS}, 100 \mathrm{U} / \mathrm{ml}$ penicillin and $100 \mu \mathrm{g} / \mathrm{ml}$ streptomycin. DNA transfections were carried out by using Fugene-6 or FugeneHD (Roche, Basel, Switzerland), and siRNA transfections were performed by using Oligofectamine (Invitrogen) according to the instructions provided by the manufacturer. Apoptosis treatments included UVC irradiation at the indicated dose using a Stratalinker UV Crosslinker (Stratagene, Santa Clara, CA, USA), cisplatin (10 $\mu \mathrm{g} / \mathrm{ml}$ for U2OS and HeLa cells), doxorubicin (7.5 $\mu \mathrm{M}$ for U2OS cells) and staurosporine (200 nM for U2OS cells). Where indicated, cells were pretreated for $1 \mathrm{~h}$ with the pan-caspase inhibitor QVD (R\&D Systems, Minneapolis, MN, USA; $10 \mu \mathrm{M}$ for U2OS and HeLa cells). Apoptosis was quantified by annexinV-FITC and PI double staining using a kit from Life Technology Inc. (Grand Island, NY, USA). Subcellular fractionation experiments were conducted as previously described. ${ }^{62}$

DNA plasmids, adenoviruses and siRNA. Full-length CHCHD2 cDNA was purchased from Open Biosystems (Genbank accession number NM_016139.2). Untagged and C-terminally FLAG-tagged CHCHD2 were cloned into the pcDNA3.1 vector (Invitrogen). All cloned constructs were confirmed by DNA sequencing. Recombinant adenoviruses carrying untagged $\mathrm{CHCHD} 2$ or GFP were produced by using the AdEasy XL Adenoviral Vector System (Stratagene) according to the manufacturer's protocol. siRNA duplexes targeting $\mathrm{CHCHD2}$ and $\mathrm{BCl}-\mathrm{xL}$ were purchased from Invitrogen (Stealth RNAi targeting CHCHD2\#1 5'-GGGCACACA TTGGGTCACGCCATTA-3', CHCHD2\#2 5'-GGTGACATCAAGCTCTGTGAGGGTT-3' and targeting BCl-xL 5'-GGAGATGCAGGTATTGGTG-3'), and nonspecific control siRNA was purchased from Dharmacon (Lafayette, CO, USA).

Western blotting and immunoprecipitation. After lysing cells in $0.5 \%$ NP-40 buffer, the lysates were resolved on a $12.5 \%$ polyacrylamide gel and then transferred to a $0.2-\mu \mathrm{m}$ nitrocellulose membrane. Membranes were blocked for at least $30 \mathrm{~min}$ in phosphate-buffered saline blocking buffer with $0.1 \%$ Tween-20 (PBST) and $5 \%$ non-fat dried milk. Membranes were incubated for $2 \mathrm{~h}$ to overnight with the appropriate primary antibody, incubated for $1-2 \mathrm{~h}$ in secondary HRPconjugated antibody, and exposed with Supersignal West Pico or Dura reagent (Pierce, Rockford, IL, USA). For CO-IP experiments, cells or crude mitochondria were lysed in $1 \%$ CHAPS buffer (10 mM HEPES, $150 \mathrm{mM} \mathrm{NaCl}$ and $1 \%$ CHAPS with protease inhibitor cocktail). Lysates containing $500 \mu \mathrm{g}$ to $1 \mathrm{mg}$ of protein were immunoprecipitated with the indicated antibody. The precipitated protein was resolved by SDS-PAGE and then analyzed by western blotting.

Immunofluorescence and confocal imaging. For immunofluorescence imaging, cells were fixed in $4 \%$ paraformaldehyde for $15 \mathrm{~min}$ at room temperature 
and permeabilized in $0.2 \%$ Triton X-100 for 5 min at $4{ }^{\circ} \mathrm{C}$. Fixed and permeabilized cells were blocked for $30 \mathrm{~min}$ in $0.5 \%$ BSA blocking buffer diluted in PBS, incubated with the appropriate primary antibody overnight at $4{ }^{\circ} \mathrm{C}$ with gentle shaking and then incubated with Alexa Fluor secondary antibodies ( $488 \mathrm{~nm}$ and $594 \mathrm{~nm}$ donkey antirabbit and donkey anti-mouse antibodies, respectively; Life Technology Inc.) for $1 \mathrm{~h}$ at room temperature with gentle shaking. Nuclei were stained with 4',6-diamidino-2phenylindole (DAPI), and mitochondria visualized with MitoTracker Red or other mitochondrial markers where indicated. Cells were mounted in fluorescence mounting medium (Dako, Carpinteria, CA, USA) and were analyzed by using either an Olympus FLUOVIEW FV1000 confocal laser scanning microscope or an Olympus IX81 inverted microscope (Olympus Corporation, Tokyo, Japan) combined with a SPOT digital microscope camera and imaging software (SPOT Imaging Solutions, Sterling Heights, MI, USA) as indicated.

Antibodies. Rabbit anti-CHCHD2 antibody was produced by immunizing rabbits (PRF\&L, Canadensis, PA, USA) with a KLH-conjugated peptide antigen corresponding to amino acids 94-108 of CHCHD2. Serum was affinity purified, and antibody specificity was tested by western blotting and immunofluorescence staining in the presence or absence of $\mathrm{CHCHD2}$ knockdown. The following antibodies were purchased commercially: actin (Chemicon, Billerica, MA, USA), PARP (C2-10, BD Pharmingen, San Jose, CA, USA), mtHSP70/GRP75 (H-155, Santa Cruz, Dallas, TX, USA), cytochrome $c(6 \mathrm{H} 2 . \mathrm{B} 4, \mathrm{BD}$ Pharmingen), active/ cleaved caspase-3 (Asp175, Cell Signaling, Danvers, MA, USA), Tim23 (BD Transduction Laboratories, San Jose, CA, USA), Bcl-xL (sc-634, Santa Cruz), Bax (BD Biosciences, San Jose, CA, USA), Bak (Abcam, Cambridge, MA, USA), active Bax (6A7, BD Biosciences).

Bax trypsin resistance assay. The Bax trypsin resistance assay was conducted as previously described ${ }^{40}$ with slight modifications. Briefly, mitochondria were isolated by permeabilizing the cells in $0.015 \%$ digitonin in hypotonic buffer for $3 \mathrm{~min}$ at $4^{\circ} \mathrm{C}$ followed by centrifugation at $12000 \times \mathrm{g}$ for $10 \mathrm{~min}$ at $4^{\circ} \mathrm{C}$. The resulting mitochondria-enriched pellet was incubated with trypsin $(0.17 \mathrm{mg} / \mathrm{ml})$ for $2 \mathrm{~h}$ at $30^{\circ} \mathrm{C}$ followed by treatment with trypsin inhibitor $(1.4 \mathrm{mg} / \mathrm{ml}$, Sigma, St. Louis, MO, USA). Trypsin-treated mitochondria were lysed in $0.5 \%$ Triton X-100 and analyzed by immunoblotting alongside untreated whole-cell lysates.

Statistical analysis. Data were analyzed by using Graph Pad 5.0 software (GraphPad Software, La Jolla, CA, USA). Error bars denote the S.E.M. Statistical analyses were performed based on Student's $t$-test, and $P$-values $<0.05$ were considered statistically significant $\left({ }^{*},{ }^{* *}\right.$ and ${ }^{* \star *}$ are used to indicate statistical significance corresponding to a $P$-value $<0.05, P$-value $<0.01$ and $P$-value $<0.001$, respectively). NS indicates no significant difference.

\section{Conflict of Interest}

The authors declare no conflict of interest.

Acknowledgements. We thank $\mathrm{M}$ Deshmukh and $\mathrm{A}$ Cox for helpful discussions and for their generosity in sharing reagents. This work was supported by grants from the NIH (CA100302, CA127770, CA155235 and CA167637) and NSFC (No. 81272207) to YZ and from the National Cancer Institute (Cancer Cell Biology Training Grant, 5T32CA071341) to HVC.

1. Kerr JF, Wyllie AH, Currie AR. Apoptosis: a basic biological phenomenon with wide-ranging implications in tissue kinetics. Br J Cancer 1972; 26: 239-257.

2. Chipuk JE, Moldoveanu T, Llambi F, Parsons MJ, Green DR. The BCL-2 family reunion. Mol Cell 2010; 37: 299-310.

3. Wei MC, Zong WX, Cheng EH, Lindsten T, Panoutsakopoulou V, Ross AJ et al. Proapoptotic BAX and BAK: a requisite gateway to mitochondrial dysfunction and death. Science 2001 292: 727-730.

4. Kim H, Tu HC, Ren D, Takeuchi O, Jeffers JR, Zambetti GP et al. Stepwise activation of BAX and BAK by tBID, BIM, and PUMA initiates mitochondrial apoptosis. Mol Cell 2009; 36 487-499.

5. Gavathiotis E, Reyna DE, Davis ML, Bird GH, Walensky LD. BH3-triggered structural reorganization drives the activation of proapoptotic BAX. Mol Cell 2010; 40: 481-492.

6. Ren D, Tu HC, Kim H, Wang GX, Bean GR, Takeuchi O et al. BID, BIM, and PUMA are essential for activation of the BAX- and BAK-dependent cell death program. Science 2010 330: $1390-1393$.
7. Lovell JF, Billen LP, Bindner S, Shamas-Din A, Fradin C, Leber B et al. Membrane binding by tBid initiates an ordered series of events culminating in membrane permeabilization by Bax. Cell 2008; 135: 1074-1084.

8. Kim H, Rafiuddin-Shah M, Tu HC, Jeffers JR, Zambetti GP, Hsieh JJ et al. Hierarchical regulation of mitochondrion-dependent apoptosis by BCL-2 subfamilies. Nat Cell Biol 2006; 8: $1348-1358$

9. Kuwana T, Bouchier-Hayes L, Chipuk JE, Bonzon C, Sullivan BA, Green DR et al. BH3 domains of $\mathrm{BH} 3-$ only proteins differentially regulate Bax-mediated mitochondrial membrane permeabilization both directly and indirectly. Mol Cell 2005; 17: 525-535.

10. Chipuk JE, Bouchier-Hayes L, Kuwana T, Newmeyer DD, Green DR. PUMA couples the nuclear and cytoplasmic proapoptotic function of p53. Science 2005; 309: 1732-1735.

11. Letai A, Bassik MC, Walensky LD, Sorcinelli MD, Weiler S, Korsmeyer SJ. Distinct BH3 domains either sensitize or activate mitochondrial apoptosis, serving as prototype cancer therapeutics. Cancer Cell 2002; 2: 183-192.

12. O'Connor L, Strasser A, O'Reilly LA, Hausmann G, Adams JM, Cory S et al. Bim: a novel member of the Bcl-2 family that promotes apoptosis. EMBO J 1998; 17: 384-395.

13. Wei MC, Lindsten T, Mootha VK, Weiler S, Gross A, Ashiya M et al. tBID, a membranetargeted death ligand, oligomerizes BAK to release cytochrome c. Genes Dev 2000; 14 : 2060-2071.

14. Oltvai ZN, Milliman CL, Korsmeyer SJ. Bcl-2 heterodimerizes in vivo with a conserved homolog, Bax, that accelerates programmed cell death. Cell 1993; 74: 609-619.

15. Boise LH, Gonzalez-Garcia M, Postema CE, Ding L, Lindsten T, Turka LA et al. bcl-x, a bcl-2related gene that functions as a dominant regulator of apoptotic cell death. Cell 1993; 74 : 597-608.

16. Kozopas KM, Yang T, Buchan HL, Zhou P, Craig RW. MCL1 a gene expressed in programmed myeloid cell differentiation, has sequence similarity to BCL2. Proc Natl Acad Sci USA 1993; 90: 3516-3520.

17. Perciavalle RM, Stewart DP, Koss B, Lynch J, Milasta S, Bathina M et al. Anti-apoptotic MCL-1 localizes to the mitochondrial matrix and couples mitochondrial fusion to respiration. Nat Cell Biol 2012; 14: 575-583.

18. Chen YB, Aon MA, Hsu YT, Soane L, Teng X, McCaffery JM et al. Bcl-xL regulates mitochondrial energetics by stabilizing the inner membrane potential. J Cell Biol 2011; 195: 263-276.

19. Andersen JL, Kornbluth S. The tangled circuitry of metabolism and apoptosis. Mol Cell 2013; 49: 399-410.

20. Itahana K, Zhang Y. Mitochondrial p32 is a critical mediator of ARF-induced apoptosis. Cancer Cell 2008; 13: 542-553.

21. Seo M, Lee WH, Suk K. Identification of novel cell migration-promoting genes by a functional genetic screen. FASEB J 2010; 24: 464-478.

22. Baughman JM, Nilsson R, Gohil VM, Arlow DH, Gauhar Z, Mootha VK. A computational screen for regulators of oxidative phosphorylation implicates SLIRP in mitochondrial RNA homeostasis. PLoS Genet 2009; 5: e1000590.

23. Arslantas A, Artan S, Oner U, Muslumanoglu H, Durmaz R, Cosan E et al. The importance of genomic copy number changes in the prognosis of glioblastoma multiforme. Neurosurg Rev 2004; $27:$ 58-64.

24. Shmueli O, Horn-Saban S, Chalifa-Caspi V, Shmoish M, Ophir R, Benjamin-Rodrig H et al. GeneNote: whole genome expression profiles in normal human tissues. C R Biol 2003; 326: 1067-1072.

25. Schultz J, Milpetz F, Bork P, Ponting CP. SMART, a simple modular architecture research tool: identification of signaling domains. Proc Natl Acad Sci USA 1998; 95: 5857-5864.

26. Arnesano F, Balatri E, Banci L, Bertini I, Winge DR. Folding studies of Cox17 reveal an important interplay of cysteine oxidation and copper binding. Structure 2005; 13: 713-722.

27. Nobrega MP, Bandeira SC, Beers J, Tzagoloff A. Characterization of COX19, a widely distributed gene required for expression of mitochondrial cytochrome oxidase. J Biol Chem 2002; 277: 40206-40211.

28. Chacinska A, Pfannschmidt S, Wiedemann N, Kozjak V, Sanjuan Szklarz LK, Schulze-Specking A et al. Essential role of Mia40 in import and assembly of mitochondrial intermembrane space proteins. EMBO J 2004; 23: 3735-3746.

29. Mesecke N, Terziyska N, Kozany C, Baumann F, Neupert W, Hell K et al. A disulfide relay system in the intermembrane space of mitochondria that mediates protein import. Cell 2005; 121: $1059-1069$

30. Darshi M, Trinh KN, Murphy AN, Taylor SS. Targeting and import mechanism of coiled-coil helix coiled-coil helix domain-containing protein 3 (ChChd3) into the mitochondrial intermembrane space. J Biol Chem 2012; 287: 39480-39491.

31. Darshi M, Mendiola VL, Mackey MR, Murphy AN, Koller A, Perkins GA et al. ChChd3, an inner mitochondrial membrane protein, is essential for maintaining crista integrity and mitochondrial function. J Biol Chem 2011; 286: 2918-2932.

32. An J, Shi J, He Q, Lui K, Liu Y, Huang Y et al. CHCM1/CHCHD6, novel mitochondrial protein linked to regulation of mitofilin and mitochondrial cristae morphology. J Biol Chem 2012; 287: $7411-7426$.

33. Claros MG, Vincens P. Computational method to predict mitochondrially imported proteins and their targeting sequences. Eur J Biochem 1996; 241: 779-786.

34. Simbulan-Rosenthal CM, Rosenthal DS, lyer S, Boulares AH, Smulson ME. Transient poly (ADP-ribosyl)ation of nuclear proteins and role of poly(ADP-ribose) polymerase in the early stages of apoptosis. J Biol Chem 1998; 273: 13703-13712. 
35. Arnoult D. Apoptosis-associated mitochondrial outer membrane permeabilization assays. Methods 2008; 44: 229-234.

36. Martinou JC, Desagher S, Antonsson B. Cytochrome $\mathrm{c}$ release from mitochondria: all or nothing. Nat Cell Biol 2000; 2: E41-E43.

37. Willis SN, Chen L, Dewson G, Wei A, Naik E, Fletcher Jl et al. Proapoptotic Bak is sequestered by $\mathrm{Mcl}-1$ and $\mathrm{Bcl}-\mathrm{xL}$, but not $\mathrm{Bcl}-2$, until displaced by BH3-only proteins. Genes Dev 2005; 19: 1294-1305.

38. Edlich F, Banerjee S, Suzuki M, Cleland MM, Arnoult D, Wang C et al. Bcl-x(L) retrotranslocates bax from the mitochondria into the cytosol. Cell 2011; 145: 104-116.

39. Wolter KG, Hsu YT, Smith CL, Nechushtan A, Xi XG, Youle RJ. Movement of Bax from the cytosol to mitochondria during apoptosis. J Cell Biol 1997; 139: 1281-1292.

40. Lucken-Ardjomande S, Montessuit S, Martinou JC. Bax activation and stress-induced apoptosis delayed by the accumulation of cholesterol in mitochondrial membranes. Cell Death Differ 2008; 15: 484-493.

41. Billen LP, Kokoski CL, Lovell JF, Leber B, Andrews DW. Bcl-XL inhibits membrane permeabilization by competing with Bax. PLOS Biol 2008; 6: e147.

42. Todt F, Cakir Z, Reichenbach F, Youle RJ, Edlich F. The C-terminal helix of Bcl-x $(\mathrm{L})$ mediates Bax retrotranslocation from the mitochondria. Cell Death Differ 2013; 20: 333-342.

43. Schellenberg B, Wang P, Keeble JA, Rodriguez-Enriquez R, Walker S, Owens TW et al. Bax exists in a dynamic equilibrium between the cytosol and mitochondria to control apoptotic priming. Mol Cell 2013; 49: 959-971.

44. Hsu YT, Wolter KG, Youle RJ. Cytosol-to-membrane redistribution of Bax and $\mathrm{Bcl}-\mathrm{X}(\mathrm{L})$ during apoptosis. Proc Natl Acad Sci USA 1997; 94: 3668-3672.

45. Banci L, Bertini I, Cefaro C, Ciofi-Baffoni S, Gallo A, Martinelli M et al. MIA40 is an oxidoreductase that catalyzes oxidative protein folding in mitochondria. Nat Struct Mol Biol 2009; 16: 198-206.

46. Aras S, Pak O, Sommer N, Finley Jr R, Huttemann M, Weissmann N et al. Oxygendependent expression of cytochrome $\mathrm{c}$ oxidase subunit 4-2 gene expression is mediated by transcription factors RBPJ, CXXC5 and CHCHD2. Nucleic Acids Res 2013; 41: 2255-2266.

47. Hanahan D, Weinberg RA. The hallmarks of cancer. Cell 2000; 100: 57-70.

48. Hanahan D, Weinberg RA. Hallmarks of cancer: the next generation. Cell 2011; 144: 646-674.

49. Sorlie T, Tibshirani R, Parker J, Hastie T, Marron JS, Nobel A et al. Repeated observation of breast tumor subtypes in independent gene expression data sets. Proc Natl Acad Sci USA 2003; 100: 8418-8423.

50. Pyeon D, Newton MA, Lambert PF, den Boon JA, Sengupta S, Marsit CJ et al. Fundamental differences in cell cycle deregulation in human papillomavirus-positive and human papillomavirus-negative head/neck and cervical cancers. Cancer Res 2007; 67: 4605-4619.

51. Liang Y, Diehn M, Watson N, Bollen AW, Aldape KD, Nicholas MK et al. Gene expression profiling reveals molecularly and clinically distinct subtypes of glioblastoma multiforme. Proc Natl Acad Sci USA 2005; 102: 5814-5819.

52. Andersson A, Ritz C, Lindgren D, Eden P, Lassen C, Heldrup J et al. Microarray-based classification of a consecutive series of 121 childhood acute leukemias: prediction of leukemic and genetic subtype as well as of minimal residual disease status. Leukemia 2007; 21: 1198-1203.

53. Landi MT, Dracheva T, Rotunno M, Figueroa JD, Liu H, Dasgupta A et al. Gene expression signature of cigarette smoking and its role in lung adenocarcinoma development and survival. PLoS One 2008; 3: e1651.

54. Storz MN, van de Rijn M, Kim YH, Mraz-Gernhard S, Hoppe RT, Kohler S. Gene expression profiles of cutaneous B cell lymphoma. J Invest Dermatol 2003; 120: 865-870.

55. Haqq C, Nosrati M, Sudilovsky D, Crothers J, Khodabakhsh D, Pulliam BL et al. The gene expression signatures of melanoma progression. Proc Natl Acad Sci USA 2005; 102: 6092-6097.

56. Gordon GJ, Rockwell GN, Jensen RV, Rheinwald JG, Glickman JN, Aronson JP et al. Identification of novel candidate oncogenes and tumor suppressors in malignant pleural mesothelioma using large-scale transcriptional profiling. Am J Pathol 2005; 166: 1827-1840.

57. Zhan F, Barlogie B, Arzoumanian V, Huang Y, Williams DR, Hollmig K et al. Geneexpression signature of benign monoclonal gammopathy evident in multiple myeloma is linked to good prognosis. Blood 2007; 109: 1692-1700.

58. Albino D, Scaruffi P, Moretti S, Coco S, Truini M, Di Cristofano C et al. Identification of low intratumoral gene expression heterogeneity in neuroblastic tumors by genome-wide expression analysis and game theory. Cancer 2008; 113: 1412-1422.

59. Pei H, Li L, Fridley BL, Jenkins GD, Kalari KR, Lingle W et al. FKBP51 affects cancer cell response to chemotherapy by negatively regulating Akt. Cancer Cell 2009; 16: 259-266.

60. Tomlins SA, Mehra R, Rhodes DR, Cao X, Wang L, Dhanasekaran SM et al. Integrative molecular concept modeling of prostate cancer progression. Nat Genet 2007; 39: 41-51.

61. Yusenko MV, Kuiper RP, Boethe T, Ljungberg B, van Kessel AG, Kovacs G.. High-resolution DNA copy number and gene expression analyses distinguish chromophobe renal cell carcinomas and renal oncocytomas. BMC Cancer 2009; 9: 152.

62. Itahana K, Mao H, Jin A, Itahana Y, Clegg HV, Lindstrom MS et al. Targeted inactivation of Mdm2 RING finger E3 ubiquitin ligase activity in the mouse reveals mechanistic insights into p53 regulation. Cancer Cell 2007; 12: 355-366.

\section{Supplementary Information accompanies this paper on Cell Death and Differentiation website (http://www.nature.com/cdd)}

